\title{
Influence of deposition conditions on the composition of tantalum coatings
}

\author{
I. V. Sapegina ${ }^{\dagger, 1}$, O. Y. Goncharov ${ }^{1}$, V. I. Lad’yanov ${ }^{1}$, L. H. Baldaev ${ }^{2}$ \\ †sairvl@mail.ru \\ ${ }^{1}$ Udmurt Federal Research Center Ural Branch of RAS, 34 Tatyana Baramzina St., Izhevsk, 426000, Russia \\ ${ }^{2}$ OOO “Technological systems for protective coatings”, 19 Simferopol shosse, Moscow, 108852, Russia
}

In this paper, tantalum coatings obtained by the chemical vapour deposition in reactors with "hot" and "cold" walls were analyzed. Holder with a sample was put into the tube-shaped screen to limit the interaction zone in the reaction chamber. Screens from different materials were used: one from the quartz glass and the other one from the stainless steel. Induction heating was used to heat the substrates in the reactor. The inductor coil was located on the outside surface of the screen. In the case of quartz glass screen, only the holder with the sample was heated which corresponds to the reactor with the "cold" walls. When the screen made from stainless steel was used, the heat transfer from the screen walls to the sample occurred and this corresponded to the "hot" wall reactor scenario. Tantalum coatings were produced on tungsten substrates by the reduction of tantalum bromide with cadmium vapour. It was found out that the formation of reverse flows containing products of chemical reaction and the non-reacting reagents during deposition of coatings was possible due to the effect of ejection. As a result, in a reactor with "hot" walls, part of the reagents interacted with the surface of the stainless steel screen, which led to the formation of $\mathrm{Fe}_{2} \mathrm{Br}_{4}$ and $\mathrm{CrBr}_{2}$, and the subsequent reduction of not only tantalum bromide, but also iron bromide on the substrate. Thus, the tantalum coating was formed on the sample during the deposition in the reactor with "cold" walls, and the coating consisting of a mixture of $\mathrm{Ta}+\mathrm{Fe}_{2} \mathrm{Ta}$ was formed using a reactor with "hot" walls.

Keywords: CVD, tantalum, coating composition.

УДК: 621.793

\section{Влияние условий осаждения на состав танталовых покрытий}

\author{
Сапегина И. В. ${ }^{\dagger, 1}$, Гончаров О. Ю. ${ }^{1}$, Ладьянов В. И. ${ }^{1}$, Балдаев Л. Х. ${ }^{2}$ \\ †sairvl@mail.ru
}

${ }^{1}$ Удмуртский федеральный исследовательский центр УрО РАН, ул. им. Татьяны Барамзиной, 34, Ижевск, 426067, Россия ${ }^{2} \mathrm{OOO}$ «Технологические системы защитных покрытий», Симферопольское шоссе, 19, Москва, 108852, Россия

В данной работе был проведен анализ покрытий из тантала, полученных методом химического газофазного осаждения в реакторах с «горячими» и с «холодными» стенками. Для ограничения зоны взаимодействия в реакционной камере, использовали экран в виде трубки, внутри которого располагался держатель с образцом. Экран изготавливали из разных материалов - кварцевое стекло и нержавеющая сталь. Для нагрева подложек в реакторе использовался индукционный нагрев, катушка индуктора была расположена с внешней стороны экрана. В случае применения экрана из кварцевого стекла нагревался только держатель с образцом, что соответствовало реактору с «холодными» стенками. При использовании экрана из нержавеющей стали, образец нагревался за счет теплопередачи от стенок экрана, то есть реализовывался вариант реактора с «горячими» стенками. Было проведено осаждение тантала на вольфрамовые подложки восстановлением бромида тантала парами кадмия. Выяснено, что в процессе получения покрытий из-за эффекта эжекции возможно образование обратных течений, содержащих непрореагировавшие реагенты и продукты реакции. В результате, при использовании реактора с «горячими» стенками часть реагентов взаимодействует с поверхностью экрана из нержавеющей стали, что приводит к образованию $\mathrm{Fe}_{2} \mathrm{Br}_{4}$ и $\mathrm{CrBr}_{2}$, и последующему восстановлению на подложке не только бромида тантала, но и бромида железа. Таким образом, при осаждении в реакторе с «холодными» стенками на образце формируется танталовое покрытие, а при использовании реактора с «горячими» стенками - покрытие, состоящее из смеси $\mathrm{Ta}+\mathrm{Fe}_{2} \mathrm{Ta}$.

Ключевые слова: ХГО, тантал, состав покрытия. 


\section{1. Введение}

Широко применяемые газофазные методы осаждения $[1,2]$, позволяют получать материалы и покрытия высокой чистоты, а также управлять составом и структурой покрытий. При газофазном осаждении конденсация компонентов покрытий на поверхности изделий может проводиться физическими методами (PVD - Physical Vapour Deposition) [3-5] или методами химического осаждения (CVD - Chemical Vapour Deposition) [6-9]. В основном CVD-установки содержат в своем составе следующие основные системы: 1) блок подачи газов; 2) блок утилизации отработанных газов; 3) блок испарителей, задающих концентрации реагентов-прекурсоров; 4) реакционная камера (реактор) [10]. Относительно температуры подложки реакторы для осуществления CVD-процесса делятся на реакторы с «горячими» и с «холодными» стенками [11]. Когда стенки реактора, окружающие нагретую подложку, относительно холодны по сравнению с ней, реактор считается холодностенным. В реакторах с «горячими» стенками подложка, на которой идет осаждение из газовой фазы, нагревается за счет теплопередачи от стенок реактора. Однако, при этом взаимодействие паров реагентов с образованием твердой фазы под действием температуры может происходить как на поверхности подложки, так и непосредственно в газовой фазе и на стенках реактора [12]. Поэтому при получении покрытий необходимо учитывать взаимодействие применяемых реагентов с материалом реактора и как это может повлиять на состав покрытия. В данной работе было проведен анализ покрытий из тантала, полученных CVD-методом в реакторах с «горячими» и с «холодными» стенками.

\section{2. Материалы и методы исследования}

Покрытия наносили в CVD-установке [13], которая позволяет проводить безводородное осаждение тугоплавких соединений, предложенным нами методом газофазного восстановления галогенидов тугоплавких металлов (например, $\mathrm{TaBr}_{5}$ ) парами металлов второй группы (например, кадмием) [14-17]. В реакторном блоке установки размещены испарители реагентов и предусмотрена подача реагентов по раздельным каналам, что предотвращает их преждевременное взаимодействие. Один испаритель был использован для пода- чи паров $\mathrm{TaBr}_{5}$, второй служил для испарения кадмия (газ-носитель - гелий). Покрытия наносили при атмосферном давлении на плоские подложки размером $1 \times 1 \times 0.3 \mathrm{~cm}$, изготовленные из вольфрама (99.3 мас.\%), предварительные исследования вольфрамовых подложек методом оптической эмиссионной спектрометрии с тлеющим разрядом показали наличие в них примеси железа до 0.7 мас.\%. Условия нанесения тантала представлены в Табл. 1. Для ограничения зоны взаимодействия в реакционной камере, использовали экран в виде трубки с внутренним диаметром 4.5 см и длиной 15.5 см, внутри которого располагался держатель с образцом. Верхняя часть экрана плотно прилегает к плоскости соплового блока, нижняя часть - ко дну реакционной камеры. Применяли экраны, изготовленные из разных материалов - кварцевое стекло и сталь 12Х18Н10Т. Использовался индукционный нагрев подложек в реактоpe, катушка индуктора расположена с внешней стороны экрана. В случае применения экрана из кварцевого стекла нагревалась только сама подложка, что соответствует реактору с «холодными» стенками. При использовании экрана из нержавеющей стали, образец нагревался за счет теплопередачи от стенок экрана, то есть реализовывался вариант реактора с «горячими» стенками.

Фазовые состояния покрытий определяли с использованием рентгеновского дифрактометра ДРОН-6 Сo-К излучении, для идентификации фаз по рентгенодифракционным данным использовали пакет программ [18]. Послойный анализ и измерение толщины покрытий проводили с помощью оптического эмиссионного спектрометра тлеющего разряда GDA $650 \mathrm{HR}$.

\section{3. Результаты и обсуждение}

Качественный рентгенофазовый анализ показал, что на вольфраме, при ограничении зоны реакции с помощью экрана из кварцевого стекла, наносится покрытие из тантала, имеющего тетрагональную решетку ( $\beta$-Та) (Рис. 1a). Из послойного анализа образца (Рис. 2 a) следует, что толщина покрытия около 2.5 мкм. Ширина диффузного слоя около 1.2 мкм и концентрация тантала в нем довольно быстро уменьшается с толщиной, несмотря на неограниченную растворимость тантала в вольфраме [19]. В случае, когда использовался экран из нержавеющей стали, в танталовом покрытии обнаружено железо. Из Рис. 2 b видно, что слой тантала имеет толщину порядка 1 мкм и наблюдается

Таблица 1. Условия осаждения тантала.

Table 1. Conditions for the deposition of tantalum.

\begin{tabular}{|c|c|c|c|c|}
\hline $\begin{array}{c}\text { Подложка (номер образца) } \\
\text { Substrate (№ sample ) }\end{array}$ & $\begin{array}{c}\text { Материал экрана } \\
\text { Screen material }\end{array}$ & $\begin{array}{c}\text { Т подложки, } \mathrm{K} \\
\text { T substrate, } \mathrm{K}\end{array}$ & $\begin{array}{c}\text { Расстояние от сопла до образца, см } \\
\text { Distance from the nozzle to the substrate, cm }\end{array}$ & $\begin{array}{c}t, \mathrm{u} \\
t, \mathrm{~h}\end{array}$ \\
\hline $\mathrm{W}(1)$ & $\begin{array}{c}\text { кварцевое стекло } \\
\text { quartz glass }\end{array}$ & 1023 & 2.5 & 0.5 \\
\hline $\mathrm{W}(2)$ & $\begin{array}{c}\text { 12X18H10T } \\
\text { AISI 304 }\end{array}$ & 1023 & 2.5 & 0.5 \\
\hline
\end{tabular}




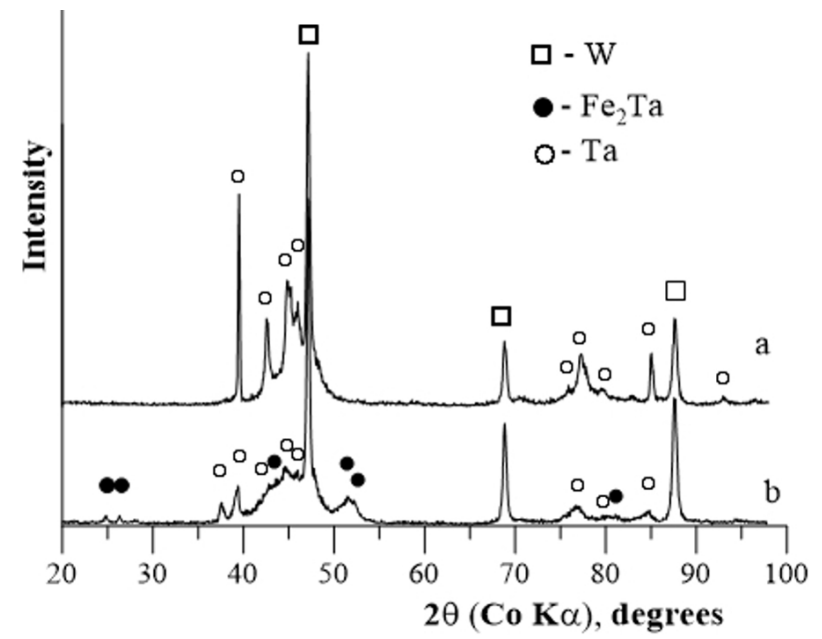

Рис. 1. Рентгеновские дифрактограммы покрытий на образце 1 (a), образце 2 (b).

Fig. 1. XRD patterns of coating in sample 1 (a), sample 2 (b).

присутствие железа по всей толщине покрытия. Концентрация железа практически не меняется по толщине танталового слоя и составляет около 5 мас.\%, затем спадает до 0.7 мас.\% в вольфрамовой подложке. По данным рентгеновской дифракции на вольфрамовом образце, кроме $\beta$-Тa, присутствует интерметаллид $\mathrm{Fe}_{2} \mathrm{Ta}$ (Рис. 1b). То есть получилось не однофазное покрытие, а смесь тантала и интерметаллида железа с танталом. При сравнении дифрактограмм от образцов 1 и 2 (Рис. $2 \mathrm{a}$ и $2 \mathrm{~b}$, соответственно), видно, что пики от покрытия, состоящего из двух фаз, сильно уширены. Это свидетельствует о большей дисперсности покрытия $\mathrm{Ta}+\mathrm{Fe}_{2} \mathrm{Ta}$, чем у слоя, состоящего только из тантала.

Поскольку остальные условия нанесения тантала на вольфрамовую подложку в обоих случаях одинаковы (температура подложки $750^{\circ} \mathrm{C}$, расстояние от сопла до образца 2.5 см), можно полагать, что железо попало в покрытие с экрана, изготовленного из ста-

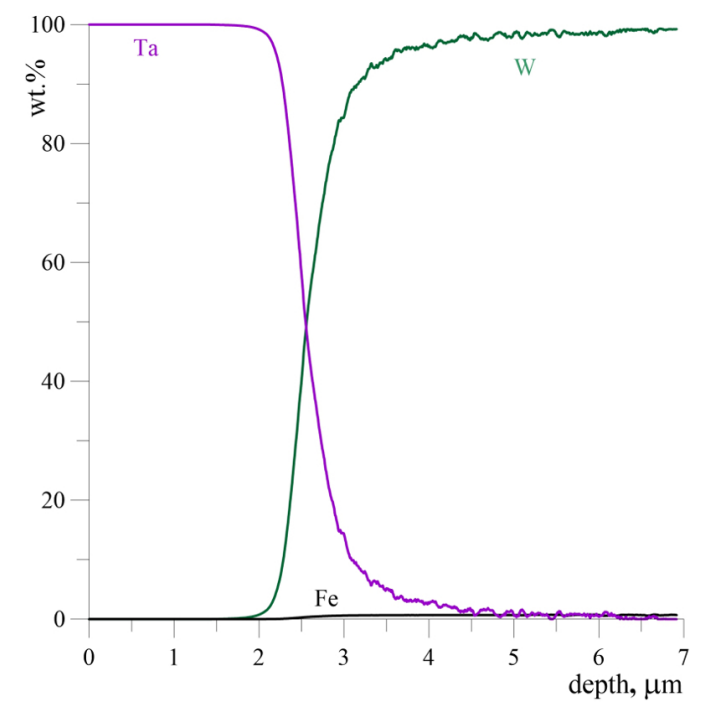

a ли 12Х18Н10Т. При исследовании внутренней поверхности экрана обнаружено изменение в фазовом составе по высоте (Рис. 3 a). На самом верху (область 1, высотой около 1.5 см) поверхность экрана соответствует нержавеющей стали. Однако в следующей, довольно широкой и наиболее нагретой части (область 2, высотой около 8 см), на поверхности выявлено присутствие тантала. На Рис. 3 b приведен профиль послойного анализа, полученного с верхней части области 2 на Рис. 3 а. Танталовая пленка не сплошная, поскольку в послойном анализе одновременно с танталом присутствуют элементы, относящиеся к нержавеющей стали. В нижней наиболее холодной части (область 3 , высотой около 6 см), танталовый слой не образуется, но, кроме элементов, относящихся к нержавеющей стали, регистрируются следы кадмия.

По-видимому, в процессе истечения газа из сопла с большой скоростью, происходит разряжение газа в районе между потоком и экраном, что приводит к образованию обратных течений, содержащих непрореагировавшие реагенты и продукты реакции. Сформировавшиеся течения, позволяют парам $\mathrm{TaBr}_{5}$ достичь металлической трубки, а также транспортировать продукты реакции на вольфрамовый образец. По данным термодинамического анализа [20] в системе $\mathrm{TaBr}_{5}$-Сd-сталь при $800 \mathrm{~K}$ и выше возможно образование газообразных бромидов $\mathrm{Fe}_{2} \mathrm{Br}_{4}$ и $\mathrm{CrBr}_{2}$, причем хром более активный и способен восстанавливать бромид тантала, конкурируя с кадмием. При температурах ниже 1000 К хром при взаимодействии с пентабромидом тантала может образовывать твердый бромид $\mathrm{CrBr}_{2}$. Таким образом, возможно внесение в основной поток газообразных бромида железа и хрома. В этом случае на подложке происходит не только восстановление бромида тантала, но и бромида железа, и формируется двухфазное покрытие $\mathrm{Ta}+\mathrm{Fe}_{2} \mathrm{Ta}$. Следует отметить, что при послойном анализе образца 2 элемент хром не был обнаружен, то есть восстановление или осаждение бромида хрома не происходит, и он удаляется вместе с остальными продуктами реакции. Некоторое уменьшение толщины покрытия на образце, веро-

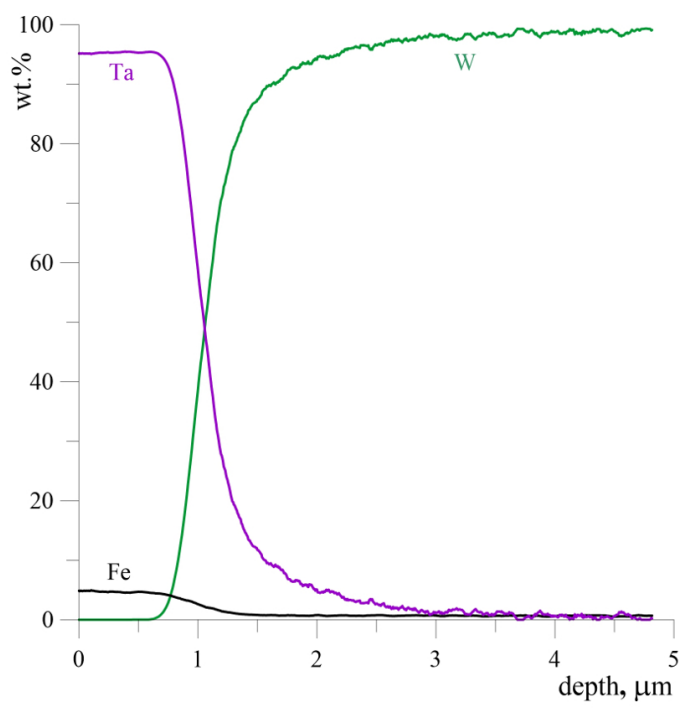

$\mathrm{b}$

Рис. 2. Профиль послойного анализа покрытия на образце 1 (a), образце 2 (b).

Fig. 2. Depth profile of the sample 1 (a), sample 2 (b). 


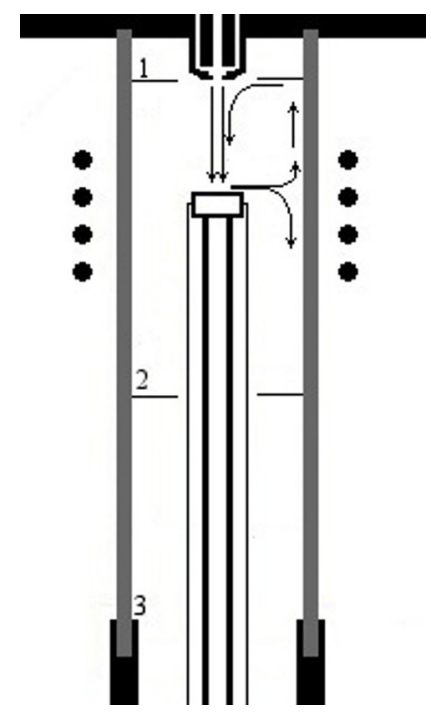

a

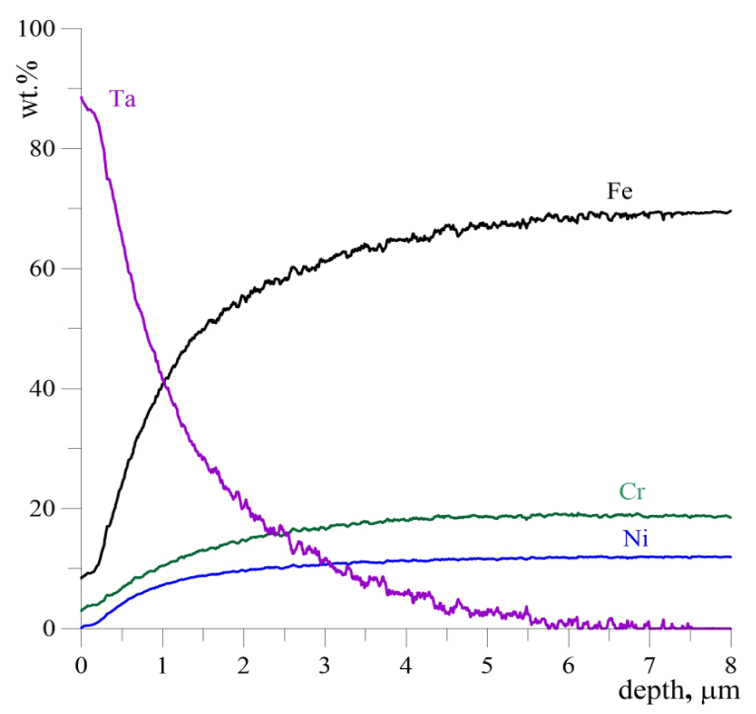

b

Рис. 3. Схематическое изображение потоков при нанесении покрытий, 1-3 - области поверхности экрана разного фазового состава (a), профиль послойного анализа экрана с области 2 (b).

Fig. 3. Schematic representation of flow during deposition of coatings, 1-3 - parts of the screen surface of different phase composition (a), depth profile of the screen in part 2 (b).

ятно, связано, с одной стороны, не полным вступлением в реакцию пентабромида тантала на подложке, часть его расходуется на взаимодействие с экраном, с другой стороны, участием части кадмия в восстановлении бромида железа.

\section{4. Выводы}

Проведен сравнительный анализ покрытий из тантала, полученных CVD-методом в реакторах с «горячими» и с «холодными» стенками. Было выяснено, что при нанесении тантала из-за эффекта эжекции возможно образование обратных течений, содержащих непрореагировавшие реагенты и продукты реакции. В результате, при использовании реактора с «горячими» стенками, сделанного из нержавеющей стали, происходит: 1) потеря части реагентов из-за реакций, происходящих на поверхности экрана; 2) внесение в основной поток газообразных продуктов реакции бромида тантала со стенками экрана $\left(\mathrm{Fe}_{2} \mathrm{Br}_{4}\right.$ и $\left.\left.\mathrm{CrBr}_{2}\right) ; 3\right)$ восстановление на подложке не только бромида тантала, но и бромида железа. Таким образом, при осаждении в реакторе с «холодными» стенками на образце формируется танталовое покрытие, а при использовании реактора с «горячими» стенками - покрытие, состоящее из смеси тантала и интерметаллида железа с танталом $\mathrm{Ta}+\mathrm{Fe}_{2} \mathrm{Ta}$.

\section{Литература/References}

1. G. G. Fuentes, E. Almandoz, R. J. Rodríguez, H. Dong, Y. Qin, S. Mato. Manufacturing Rev. 20 (1), 1 (2014). DOI: $10.1051 / \mathrm{mfreview} / 2014019$

2. Ed. by A. S. H. Makhlouf, I. Tiginyanu. Nanocoatings and ultra-thin films: technologies and applications. Oxford, Woodhead Pub. (2011) 428 p.

3. A. Mubarak, E. Hamzah, M. R. M. Toff. Jurnal Mekanikal. 20 (2), 42 (2005)
4. M. Stueber, H. Holleck, H. Leiste, K. Seemann, S. Ulrich, C. Ziebert. Journal of Alloys and Compounds. 483 (1-2), 321 (2009). DOI: 10.1016/j.jallcom.2008.08.133

5. A.D. Dobrzańska-Danikiewicz. JAMME. 54 (1), 103 (2012).

6. H. O. Pierson. Handbook of Chemical Vapor Deposition. New York, Noyes Publications, (1999). 506 p.

7. V.G. Syrkin. The CVD-method. Chemical vapor deposition. Moscow, Nauka. (2000). 496 p. (in Russian) [В.Г. Сыркин. CVD-метод. Химическое парофазное осаждение. Москва, Наука. (2000). 496 с.]

8. Chemical Vapour Deposition: Precursors, Processes and Applications (Eds.A. C. Jones, M.L. Hitchman). Cambridge, Royal Society of Chemistry. (2009). 582p.

9. S.M. George. Chem. Rev. 110 (1), 111 (2010). DOI: $10.1021 /$ cr900056b

10. D. Loktev, E. Yamashkin. Nanoindustry. 1 (4), 18 (2007). (in Russian) [Д. Локтев, Е. Ямашкин. Наноиндустрия. 1 (4), 18 (2007).]

11. A. Sarangan. Nanofabrication: Principles to Laboratory Practice. Boca Raton, CRC Press. (2016). 299p.

12. K. J. Hüttinger. CVD. 4 (4), (1998) 151. DOI: 10.1002/(SICI)1521-3862(199807)04:04<151::AIDCVDE151>3.0.CO;2-2

13. O.Yu. Goncharov, R.R. Faizullin, V.N. Guskov, L. Kh. Baldaev. News Academy of Engineering Sciences n. a. A. M. Prokhorov. 3 (4), 3 (2015). (in Russian) [О.Ю. Гончаров, Р.Р. Файзуллин, В.Н. Гуськов, Л.Х. Балдаев. Изв. Академии инженерных наук им. А. М. Прохорова. 3 (4), 3 (2015).]

14. O. Yu. Goncharov, R.R. Fajzulin, M.G. Shadrin. Neorganicheskie Materialy. 35 (10), 1057 (1999). (in Russian) [О.Ю. Гончаров, Р.Р. Файзуллин, М.Г. Шадрин. Неорган. материалы. 35 (10), 1057 (1999).]

15. O. Yu. Goncharov, M.F. Kanunnikov, R. R. Fajzulin, M. G. Shadrin. Neorganicheskie Materialy. 35 (10), 1161 
(1999). (in Russian) [О. Ю. Гончаров, М. Ф. Канунников, P. Р. Файзуллин, М.Г. Шадрин. Неорган. материалы. 35 (10), 1161 (1999).]

16. O. Yu. Goncharov, R.R. Faizullin, V.N. Guskov, L. Kh. Baldaev. Inorganic Materials. 51 (6), 593 (2015). (in Russian) [О.Ю. Гончаров, Р.Р. Файзуллин, В.Н. Гуськов, Л.Х. Балдаев. Неорган. материалы. 51 (6), 655 (2015)]. DOI: 10.1134/s0020168515060059

17. O.Yu. Goncharov, S.Yu. Treshchev, V.I. Lad'yanov, R. R. Faizullin, V.N. Guskov, L. Kh. Baldaev. Inorganic Materials. 53 (10), 1064 (2017). (in Russian) [О.Ю. Гончаров, С.Ю. Трещев, В.И. Ладьянов, P.P. Файзуллин, В.Н. Гуськов, Л.Х. Балдаев. Неорган. материалы. 53 (10), 1087 (2017).] DOI: $10.1134 /$ S0020168517100089
18. N.P. D’yakonova, E.V. Shelekhov, T.A. Sviridova, A. A. Reznikov. Zavod. Lab. 63 (10), 17 (1997). (in Russian) [Н.П. Дьяконова, Е.В. Шелехов, Т.А. Сверидова, А. А. Резников. Зав. лаборатория. 63 (10), 17 (1997).]

19. Ed. by N. P. Liakishev. State diagrams of double metallic systems. Moscow, Mashinostroyeniye (1997) 1024 p. (in Russian) [Под редакцией Н.П. Лякишева. Диаграммы состояния двойных металлических систем. Москва, Машиностроение (1997) 1024 с.]

20. O. Yu. Goncharov, R.R. Faizullin, V.N. Guskov, L. Kh. Baldaev. Inorganic Materials. 52 (3), 274 (2016). (in Russian) [О.Ю. Гончаров, P.P. Файзуллин, В.Н. Гуськов, Л.Х. Балдаев. Неорган. материалы. 52 (3), 315 (2016)]. DOI: $10.1134 / \mathrm{s} 0020168516030031$ 